\title{
6

\section{Impact of COVID-19 on Endoscopy Training: Perspectives from a Global Survey of Program Directors and Endoscopy Trainers}

\author{
Shivakumar Vignesh', Amna Subhan Butt ${ }^{2}$, Mohamed Alboraie ${ }^{3}$, Bruno Costa Martins ${ }^{4}$, Alejandro Piscoya ${ }^{5}$, Quang Trung $\operatorname{Tran}^{6}$, \\ Damien Tan Meng Yew ${ }^{7}$, Shahriyar Ghazanfar ${ }^{8}$, Pezhman Alavinejad ${ }^{9}$, Edna Kamau ${ }^{10}$, Ajay M Verma ${ }^{11}$, Robin B Mendelsohn ${ }^{12}$, \\ Christopher Khor ${ }^{13}$, Alan Moss ${ }^{14}$, David Wei Chih Liao ${ }^{15}$, Christopher S Huang ${ }^{16}$ and Franklin C Tsai ${ }^{17}$ \\ ${ }^{1}$ Division of Gastroenterology and Hepatology, Department of Medicine, SUNY Downstate Health Sciences University, Brooklyn, NY, \\ USA, ${ }^{2}$ Section of Gastroenterology, Aga Khan University Hospital, Karachi, Pakistan, ${ }^{3}$ Department of Internal Medicine, Al-Azhar \\ University, Cairo, Egypt, ${ }^{4}$ University of Sao Paulo Institute of Cancer of Sao Paulo State, Sao Paulo, Brazil, ${ }^{5}$ Hospital Guillermo Kaelin \\ de la Fuente, EsSalud, Lima, Peru, ${ }^{6}$ Department of Internal Medicine, Hue University of Medicine and Pharmacy, Hue University, Hue \\ City, Vietnam, ${ }^{7}$ Department of Gastroenterology, Duke, NUS Medical School, Singapore General Hospital, Singapore, Singapore, \\ ${ }^{8}$ Department of Surgery, Civil Hospital Karachi, Dow University of Health Sciences, Karachi, Pakistan, ${ }^{9}$ Alimentary Tract Research \\ Center, Ahvaz Jundishapur University of Medical Sciences, Ahvaz, Iran, ${ }^{10}$ Department of Clinical medicine and Therapeutics \\ University of Nairobi, Nairobi, Kenya, ${ }^{11}$ Consultant Gastroenterologist \& Physician Kettering General Hospital NHS, Kettering, UK, \\ ${ }^{12}$ Gastroenterology, Hepatology and Nutrition Service, Department of Medicine, Memorial Sloan Kettering Cancer Center, NY, USA, \\ ${ }^{13}$ Department of Gastroenterology \& Hepatology, Singapore General Hospital, Duke-NUS Medical School, Singapore, Singapore, \\ ${ }^{14}$ Western Health and University of Melbourne, Melbourne, Australia, ${ }^{15}$ Department of Internal Medicine National Taiwan University \\ Hospital, Taipei, Taiwan, ${ }^{16}$ Section of Gastroenterology, Boston University School of Medicine, Boston, ${ }^{17}$ Division of Gastroenterology, \\ Scripps Clinic - Scripps Green Hospital, Scripps Green Hospital, San Diego, USA
}

Background/Aims: The coronavirus disease of 2019 (COVID-19) pandemic has impacted the training of medical trainees internationally. The aim of this study was to assess the global impact of COVID-19 on endoscopy training from the perspective of endoscopy trainers and to identify strategies implemented to mitigate the impact on trainee education.

Methods: Teaching faculty of gastroenterology (GI) training programs globally were invited to complete a 36-question web-based survey to report the characteristics of their training programs and the impact of COVID-19 on various aspects of endoscopy training, including what factors decisions were based on.

Results: The survey response rate was 52.6\% (305 out of 580 individuals); $92.8 \%$ reported a negative impact on endoscopy training, with suspension of elective procedures $(77.1 \%$ ) being the most detrimental factor. Geographic variations were noted, with European programs reporting the lowest percentage of trainee participation in procedures. A higher proportion of trainees in the Americas were allowed to continue performing procedures, and trainers from the Americas reported receiving the greatest support for endoscopy teaching.

Conclusions: This study demonstrated that the COVID-19 pandemic has had a significant negative impact on GI endoscopy training internationally, as reported by endoscopy trainers. Focus-optimizing endoscopy training and assessment of competencies are necessary to ensure adequate endoscopy training. Clin Endosc 2021;54:678-687

Key Words: COVID-19; Endoscopy; Trainee; Trainer; Training

Received: April 28, 2021 Revised: July 25, 2021

Accepted: July 25, 2021

Correspondence: Shivakumar Vignesh

Division of Gastroenterology and Hepatology, Department of Medicine, SUNY Downstate Health Sciences University, 450 Clarkson Ave, Brooklyn, NY 11203, USA Tel: +1-203-331-5150, Fax: +1-929-275-0933, E-mail: shivakumar.vignesh@ downstate.edu

ORCID: https://orcid.org/0000-0001-5190-6222

(c) This is an Open Access article distributed under the terms of the Creative Commons Attribution Non-Commercial License (http://creativecommons.org/ licenses/by-nc/3.0) which permits unrestricted non-commercial use, distribution, and reproduction in any medium, provided the original work is properly cited.

\section{INTRODUCTION}

The coronavirus disease of 2019 (COVID-19) pandemic has impacted not only the health of people but also the learning experience of medical trainees worldwide. The virus responsible for the COVID-19 pandemic, SARS-CoV-2, spreads primarily through respiratory droplets and close contact with infected individuals. ${ }^{1,2}$ The highly infectious nature of SARS-CoV-2 and morbidity and mortality associated with 
COVID-19 have made it necessary to revise the approach to physician-patient encounters as well as trainee education. ${ }^{3-5}$ Medical centers have had to redesign their clinical, procedural, and scheduling practices to achieve physical distancing between patients and other personnel. These measures have disproportionately affected procedural specialties, such as gastroenterology (GI), due to the suspension of elective procedures as well as concerns of spreading SARS-CoV-2 during aerosol-generating endoscopic procedures. ${ }^{6,7}$

Given that endoscopy training requires close proximity between the trainee, trainer, patient, and assisting staff, attitudes and approaches to training have been substantially impacted by the COVID-19 pandemic. An international survey of GI trainees reported multiple barriers to training and variable access to training. ${ }^{8}$ A recent North American survey found that almost half of interventional endoscopy training programs had suspended endoscopic training due to the pandemic, with trainees excluded from participating in procedures in approximately half of all endoscopy units. ${ }^{9}$ The global impact of COVID-19 on endoscopy training from the perspective of GI fellowship directors and teaching faculty globally has not yet been reported. This study hypothesized that the pandemic has negatively impacted endoscopy training and that there have been geographic variations in the extent of that impact. Furthermore, this study hypothesized that the responses initiated by training programs to mitigate the impact vary between regions.

The specific aims of this study were to measure the global impact of COVID-19 on GI endoscopy training, determine the factors affecting the quality and quantity of endoscopy training, and identify strategies implemented by programs to mitigate the impact of the pandemic on trainee education and well-being.

\section{MATERIALS AND METHODS}

A voluntary, web-based survey was disseminated by email to endoscopy trainers in GI training programs around the world. The survey consisted of thirty-six questions divided into three major domains: 1) baseline characteristics of the endoscopy trainer and their training programs, 2) impact of COVID-19 on various aspects of endoscopy training, and 3) responses of the training programs to COVID-19 (Supplementary Material 1). In addition, the survey had a final free-text section where respondents were encouraged to comment on the impact of COVID-19 on their endoscopy training program. The survey was developed by members of the International Alliance of Academic Endoscopists (IAAE), who represent endoscopy trainers from 13 countries. The survey was designed to focus on endoscopy training and be applicable to international GI training programs. The survey was internally validated by a pilot test among the study team members who agreed to the final version. Endoscopy trainers, including fellowship program directors (PDs) and endoscopy training directors (ETDs) representing all World Health Organization (WHO) regions, were invited to participate in the survey.

An invitation email (Supplementary Material 2) was drafted, which included the purpose and specific objectives for conducting the survey, the link to the Google form hosting the survey, and the names of all the co-investigators and their countries of origin. In the United States, this invitation was emailed to all GI and advanced endoscopy fellowship PDs, accounting for 260 invitations. For most other countries, the invitation was emailed to PDs and teaching faculty at major academic training programs. One response was permitted per training site. The survey was also disseminated to the Education Committee, Standardization and Documentation Committee, and Standards of Practice and Publications Committee of the World Endoscopy Organization (WEO) after approval by the WEO Executive Committee (Supplementary Material 3). The invitation emails were sent between May 20 and 27, 2020. The invitation email clearly described the objectives and intent of the survey-based study, the nature of the data gathered without personal identifiers, and a plan for secure storage until data analysis was complete. This invitation email asked for consent, and recipients had the choice to participate in the survey. A reminder email was sent after one week, as needed. After receiving responses from all WHO regions, the survey was closed on June 5, 2020. The study was approved by the Institutional Review Board of the SUNY Downstate Health Sciences University, Brooklyn, USA, and was reviewed and approved by the SUNY Downstate Medical Center IRB Office under the "exempt" category.

\section{STATISTICAL ANALYSIS}

All responses were exported to Microsoft Excel (Microsoft Office 2016; WA, USA). Free text answers were categorized for the analysis. The data were transferred, coded, and analyzed using SPSS version 22.0 (IBM Corp; Armonk, NY). For descriptive analyses, the results were summarized as mean \pm $\mathrm{SD}$ and percentages for continuous and categorical variables, respectively. For comparative analyses, the t-test and Pearson's Chi-square or Fisher's exact tests were used as appropriate. All statistical tests were two-sided, and $p$-values lower than 0.05 , were considered statistically significant. In addition, multivariate analysis of variance using available variables evaluated the differences between the groups. 


\section{RESULTS}

A total of 580 teaching faculty members were invited; 305 completed the survey for a response rate of $52.6 \%$. Six responses were excluded from the analysis because they were incomplete $(n=2)$ or because the respondent did not actively teach endoscopy $(n=4)$; therefore, 299 responses were included finally.

\section{Characteristics of gastroenterology training programs and teaching faculty}

Table 1 summarizes the characteristics of the training programs and teaching faculty. Among the survey respondents, $45.8 \%, 51.8 \%$, and $70.9 \%$ were either PDs or ETDs, taught both basic and advanced endoscopy procedures, and were affiliated with academic medical centers, respectively. The number of basic and advanced endoscopy trainees per program ranged from 1 to 100 (median 8 and interquartile range [IQR] 8 ) and 1 to 30 (median 2 and IQR 3), respectively.

\section{Impact of covid-19 on gastroenterology training programs and teaching faculty}

Table 2 summarizes the impact of COVID-19 on GI training programs and teaching faculty. A total of $93.3 \%$ of participants reported a negative or strongly negative impact on endoscopy training. Suspension of elective procedures was reported by $77.1 \%$ of respondents as the single most important factor negatively impacting endoscopy training. During the COVID-19 pandemic, $31.9 \%$ of the sites did not permit trainees to perform any endoscopic procedures. A significant reduction in the average number of procedures performed by GI trainees was reported (Fig. 1), with approximately half of all respondents reporting that trainees performed fewer than five procedures per week and were involved in less than $25 \%$ of all procedures (Supplementary Figure 1). This reduction was related to multiple factors, including hospital policies (58.4\%), national policies or society guidelines (53.7\%), and a shortage of personal protective equipment (PPE) (38.9\%). The most affected procedures were esophagogastroduodenoscopy (EGD)

Table 1. The Characteristics of Gastroenterology Training Programs and Teaching Faculty ( $n=299)$

\begin{tabular}{|c|c|c|}
\hline Survey questions & Number (\%) & Mean \pm SD \\
\hline \multicolumn{3}{|l|}{ What is your role in the GI training program? } \\
\hline - Teaching faculty & $111(37.1)$ & \\
\hline$\cdot \mathrm{PD} / \mathrm{ETD}$ & $137(45.8)$ & \\
\hline - Part-time teaching faculty & $9(3.0)$ & \\
\hline - Advanced endoscopy training director & $42(14.0)$ & \\
\hline \multicolumn{3}{|l|}{ How are you involved in endoscopy training? } \\
\hline - I teach general GI procedures to trainees (e.g., EGD, colonoscopy) & $111(37.1)$ & \\
\hline - I teach general and advanced endoscopy to trainees (e.g., EGD, Colonoscopy, ERCP, EUS) & $155(51.8)$ & \\
\hline - I teach advanced endoscopy to trainees (e.g., ERCP, EUS) & $33(11.0)$ & \\
\hline \multicolumn{3}{|l|}{ Do you have an advanced endoscopy fellowship program? } \\
\hline • Yes & $176(58.9)$ & \\
\hline$\cdot$ No & $123(41.1)$ & \\
\hline \multicolumn{3}{|l|}{ What is the training setting of your program? } \\
\hline - Academic/University-based Hospital & $212(70.9)$ & \\
\hline - Community with Academic Affiliation & $41(13.7)$ & \\
\hline - Public/ Government hospital & $46(15.4)$ & \\
\hline What is the total number of general GI fellows (trainees) in your program? & & $9.8 \pm 8.8$ \\
\hline What is the duration (in years) of your general GI training program? & & $3 \pm 1$ \\
\hline How many advanced endoscopy trainees do you have in your program? & & $3.2 \pm 3.8$ \\
\hline How many faculty members in your program do you have to teach GI trainees? & & $12 \pm 10$ \\
\hline
\end{tabular}

EGD, esophagogastroduodenoscopy; ERCP, endoscopic retrograde cholangiopancreatography; ETD, endoscopy training director; EUS, endoscopic ultrasound; GI, gastroenterology; PD, program director; SD, standard deviation. 
and colonoscopy (Fig. 2). No significant differences were noted between academic medical centers and other training programs (community-based and government hospitals) regarding the impact of the COVID-19 pandemic on endoscopy training.

About $26.2 \%$ of participating programs permitted train- ees to perform procedures on COVID-19 positive patients. Factors that limited trainee participation included decisions made by the GI division (62.4\%) or PD (42.8\%), hospital policy (46.2\%), or PPE shortage (31.6\%) (Supplementary Figure 2). Almost two-thirds of the respondents noted that trainees expressed concern regarding their safety and risk of exposure

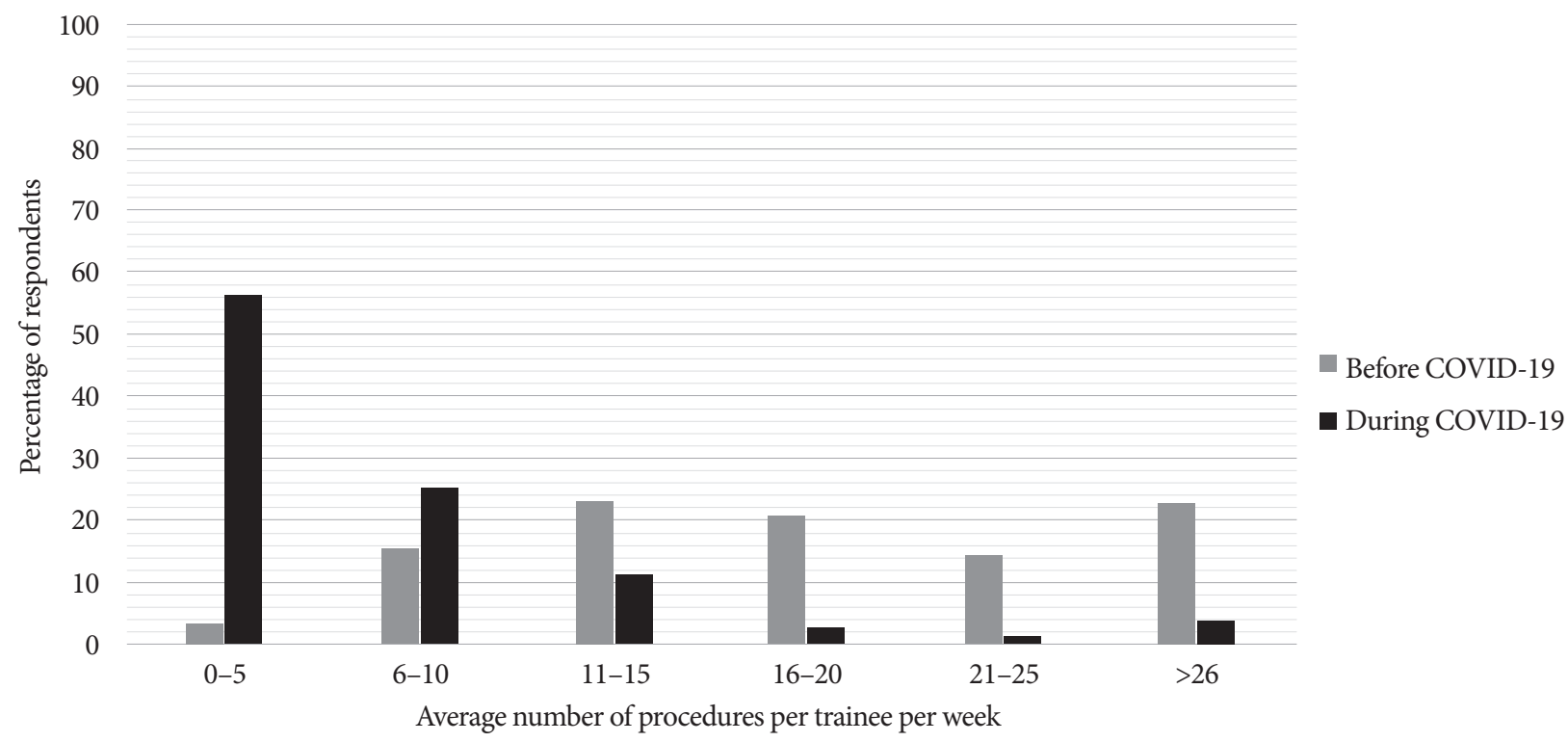

Fig. 1. Average volume of procedures performed by a trainee per week before and during COVID-19. COVID-19, the coronavirus disease of 2019.

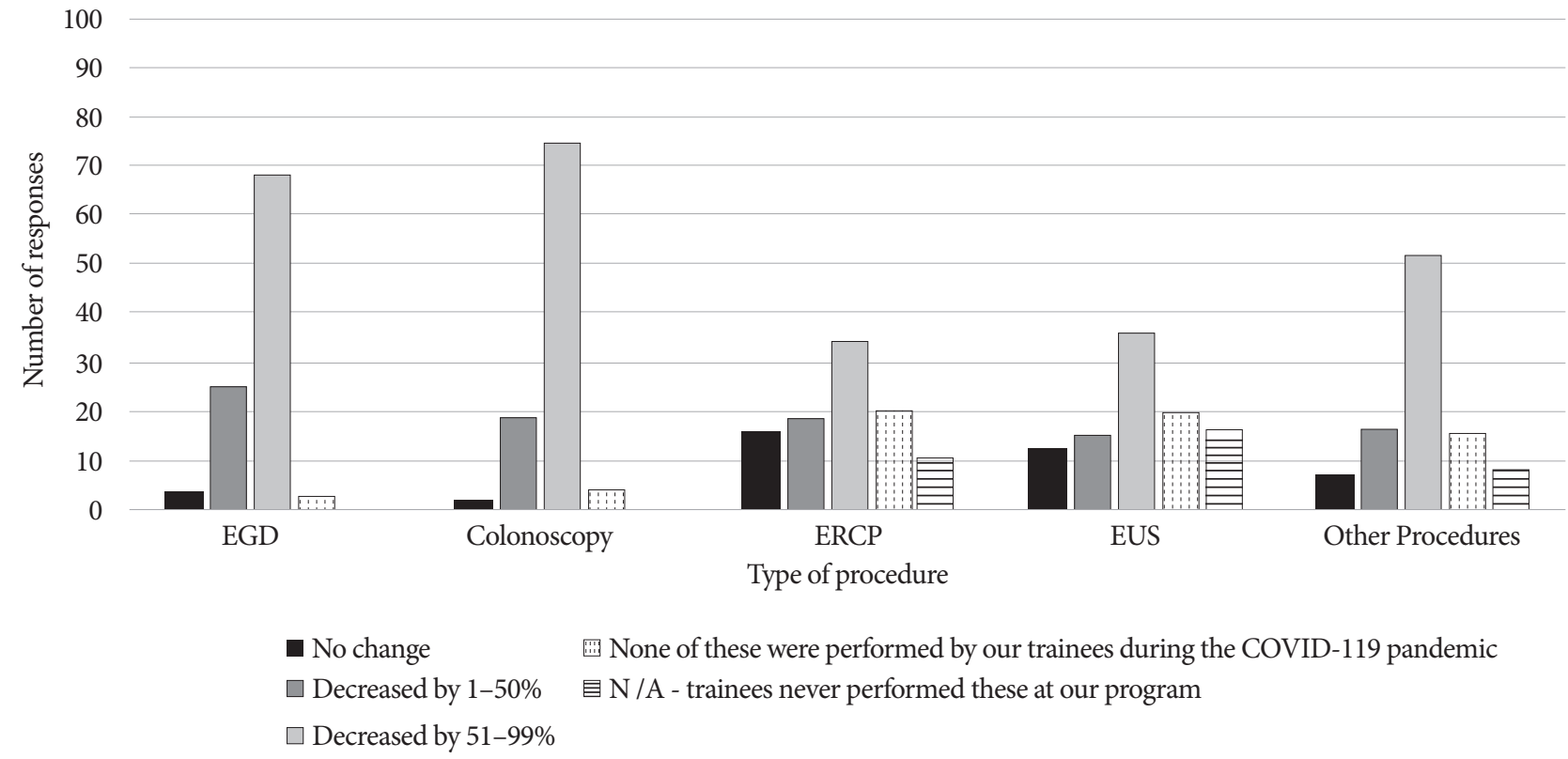

Fig. 2. Impact of the COVID-19 pandemic on the number of procedures performed by trainees per week. COVID-19, the coronavirus disease of 2019; EGD, esophagogastroduodenoscopy; ERCP, endoscopic retrograde cholangiopancreatography; EUS, endoscopic ultrasound; N/A, not available. 
(Table 2). Notably, $17.9 \%$ and $29 \%$ of participants reported having at least one trainee or faculty member, respectively, test positive for COVID-19.

Approximately one-third (34.4\%) of the respondents felt that their programs were supportive of endoscopy training, whereas others felt that the priorities were shifted away from endoscopy training or were left to the discretion of the faculty (Table 2). Additionally, 71\% of the respondents expressed concerns regarding the preparedness of the trainees to perform endoscopic procedures independently after graduation, and $25.8 \%$ felt that an extension of fellowship training might be necessary. PDs were more likely to report hospital or division policy as the cause for limiting the performance of endoscopic procedures by trainees compared with other faculties $(66.15 \%$ vs. $47.4 \%, p=0.01$; Supplementary Material 4).

On multivariate analysis, the geographical distribution of training centers in various WHO regions was strongly associated with a negative impact of the COVID-19 pandemic on endoscopy training (odd ratio $=6.4$ and $95 \%$ confidence interval $=1.83-22.33, p=0.004)$. Among the different $\mathrm{WHO}$ regions, the Americas and Southeast Asia were more negatively impacted than other regions.

Table 2. The Impact of COVID-19 on Gastroenterology Training Programs and Teaching Faculty.

\begin{tabular}{|c|c|}
\hline Survey questions & Frequency (\%) \\
\hline \multicolumn{2}{|c|}{ Has the COVID-19 pandemic affected ANY aspect of GI fellowship training at your program? $(n=299)$} \\
\hline$\cdot$ No & $20(6.7)$ \\
\hline •Yes & $279(93.3)$ \\
\hline \multicolumn{2}{|c|}{$\begin{array}{l}\text { Have your trainees been allowed to perform ANY endoscopy procedures during the COVID-19 pandemic? } \\
(n=279)\end{array}$} \\
\hline •Yes & $190(68.1)$ \\
\hline$\cdot$ No & $89(31.9)$ \\
\hline \multicolumn{2}{|c|}{ Causes of reduced endoscopy performed by trainees during the COVID-19 pandemic? $(n=190)^{*}$} \\
\hline - A decision by hospital or division & $111(58.4)$ \\
\hline - Decision by PD & $46(24.2)$ \\
\hline - Shortage of COVID-19 testing & $33(17.4)$ \\
\hline - Shortage of negative pressure rooms & $34(17.9)$ \\
\hline - Shortage of PPEs & $74(38.9)$ \\
\hline - Trainees assigned to different roles/worked offsite & $57(30)$ \\
\hline - National policy or society guidelines & $102(53.7)$ \\
\hline - Illness amongst faculty or trainees & $13(6.8)$ \\
\hline \multicolumn{2}{|c|}{ Were trainees allowed to perform procedures on COVID-19 POSITIVE patients? $(n=279)$} \\
\hline • Yes & $73(26.2)$ \\
\hline$\cdot$ No & $117(41.9)$ \\
\hline - Not answered & $89(31.9)$ \\
\hline \multicolumn{2}{|c|}{ Why were trainees not allowed to perform procedures on COVID-19 POSITIVE patients? $(n=117)^{\star}$} \\
\hline - Decision by the division & $73(62.4)$ \\
\hline$\cdot$ Hospital policy & $54(46.2)$ \\
\hline - National policy or society guidelines & $28(23.9)$ \\
\hline - Conserve PPE/Shortage of PPE & $37(31.6)$ \\
\hline - Decision by PD/to minimize exposure risk & $50(42.8)$ \\
\hline - Shortage of COVID-19 testing & $19(16.2)$ \\
\hline
\end{tabular}


Table 2. (Continued)

\section{Survey questions}

Frequency $(\%)$

What one factor had the greatest impact on endoscopy training during the COVID-19 pandemic? $(n=279)$

- Endoscopy training was minimally affected in our unit

- Suspension of elective procedures

- PPE shortage

- Trainees assigned to cover ICU/ward teams

$28(10.0)$

What were other COVID-19 factors that impacted teaching during endoscopy procedures? $(n=190)^{\star}$

- More complex or difficult procedures

- Time pressure to complete the procedure quickly

- Pressure from the nursing, anesthesiologist, or other staffing

- More difficult to interact due to distancing and PPEs

- More likely to take scope from fellow

- Impossibility of didactic meetings

- PPE availability

- Reduce exposure risk

- The main factor is the reduction of routine procedures

As an educator, did you feel endoscopy teaching was supported by your program during the COVID-19 pandemic? $(n=279)$

- Yes, endoscopy teaching was supported by my program

- No, priorities were shifted away from endoscopy teaching

- Neutral, I was left to decide how to approach endoscopy teaching

$89(31.9)$

How many confirmed COVID-19 cases have been admitted to your hospital to date? $(n=279)$

$\cdot \leq 50$

$\cdot 51-100$

$\cdot 101-250$

$\cdot 251-500$

$\cdot>500$

Did trainees express concerns regarding their safety and risk of exposure to COVID-19? $(n=279)$

- Yes

- No

- I don't know

Have trainees been asked to assume roles outside of GI? $(n=279)$

- Yes

- No

Have any of your trainees tested positive for COVID-19? $(n=279)$

- Yes

- No

- I don't know

Have any of your teaching faculty tested positive for COVID-19? ( $n=279)$

- Yes

- No 
Table 2. (Continued)

Survey questions

Frequency $(\%)$

Will the COVID-19 pandemic impact your senior fellows' preparation for performing endoscopy independently after graduation? $(n=279)$

- Maybe

$\cdot$ No

- Yes, but the fellows will likely graduate as planned

- Yes, but training may have to be extended

- Yes, senior fellows graduated early due to the demands of the COVID-19 pandemic

What has been the overall impact of the COVID-19 pandemic on the endoscopy training? $(n=279)$

- Negative impact

- Strongly negative impact

- No impact

- Positive impact

${ }^{\star}$ Recommended to check all that apply.

COVID-19, the coronavirus disease of 2019; GI, gastroenterology; ICU, intensive care unit; PD, program director; PPE, personal protective equipment.

Table 3. Strategies to Address Challenges due to COVID-19 Pandemic on GI and Endoscopy Training ( $n=279)$

\begin{tabular}{|c|c|}
\hline Survey questions & Number (\%) \\
\hline Trainees and faculty received formal training on how to care for COVID-19 patients & $218(78.1)$ \\
\hline Trainees and faculty received formal training on how to appropriately use PPE & $250(89.6)$ \\
\hline $\begin{array}{l}\text { The program has developed education focused on helping trainees cope with stress from COVID-19 and improv- } \\
\text { ing their well-being. }\end{array}$ & $139(49.8)$ \\
\hline \multicolumn{2}{|l|}{ What steps have been taken to physically distance the trainees?* } \\
\hline - Different work hour schedules for trainees & $108(38.7)$ \\
\hline - Distancing and PPE & $1(0.4)$ \\
\hline - Limiting rounds on the wards & $130(46.6)$ \\
\hline - They are assigned to other work teams & $1(0.4)$ \\
\hline - Minimizing the number of trainees in the hospital/training & $193(69.2)$ \\
\hline - Each trainee is assigned to work in a small team under one trainer & $1(0.4)$ \\
\hline - Moving trainees to different sites & $39(14.0)$ \\
\hline - Use of telemedicine and virtual conferencing & $207(74.2)$ \\
\hline \multicolumn{2}{|l|}{ What steps have been taken by your program to avoid excessive work hours for trainees?* } \\
\hline - Faculty taking on a larger role in patient care & $92(33.0)$ \\
\hline - Increased monitoring of work hours \& endorsed less working hours & $27(9.7)$ \\
\hline - Shortened rotations (for example, one week on and one week off) & $120(43.0)$ \\
\hline - Online resources & $90(32.3)$ \\
\hline -Wellness activities (for example, virtual happy hour) & $42(15.1)$ \\
\hline - Regular discussions with trainees & $100(35.8)$ \\
\hline - Theoretical and practical endoscopy teaching was postponed & $1(0.4)$ \\
\hline - No steps were taken & $55(19.7)$ \\
\hline
\end{tabular}

${ }^{\star}$ Recommended to check all that apply.

COVID-19, the coronavirus disease of 2019; GI, gastroenterology; PPE, personal protective equipment. 


\section{Measures taken by training programs to address the impact of the covid-19 pandemic on endoscopy training and trainee well-being}

Table 3 and Supplementary Figure 3 summarize the measures taken to mitigate the impact of the pandemic on endoscopy training, including formal training on PPE usage (90\%) and care for COVID-19 patients. Many centers allowed for flexibility in trainee schedules (56.3\%) and utilized virtual endoscopy education (45.9\%), although only $10.4 \%$ reported using simulators to supplement endoscopy training. Nearly half $(49.8 \%)$ of the programs implemented wellness or stress mitigation programs for trainees. Among all respondents, PDs reported more discussions with trainees to avoid burnout and support their endoscopy training (Supplementary Material 4).

\section{Comparisons between who regions}

All WHO regions are shown in Supplementary Figure 4. Comparisons between the responses from different WHO regions are summarized in Supplementary Material 5 and Supplementary Figure 5.

A higher proportion of trainees were allowed to perform endoscopy procedures in the Americas compared to other WHO regions, both in COVID-19 positive patients $(p=0.002)$ and in patients regardless of COVID-19 status $(p=0.003)$. A higher proportion of respondents from Eastern Mediterranean, African, and Southeast Asian regions felt that the pandemic would negatively impact the preparedness of trainees to perform endoscopy independently after graduation $(p<0.001)$. The utilization of online/virtual teaching was greater in the Americas and Southeast Asia than other regions $(p<0.001)$, while utilization of endoscopy simulators was highest in the Western Pacific region $(p=0.001)$ (Supplementary Material 5). Measures to manage stress and protect trainee well-being were more often adopted in the Americas and Southeast Asia $(p<0.001)$.

\section{DISCUSSION}

To the researchers' knowledge, this is the first international survey to evaluate the impact of the COVID-19 pandemic on endoscopy training from the perspective of training directors and endoscopy teachers, who are faced with the unique challenge of balancing patient care, trainee education, and the safety of all involved parties. This survey was designed to assess the factors that affected the quality and quantity of endoscopy training and to identify the strategies adopted by programs to mitigate the pandemic's impact on trainee education and well-being.
This study received responses from 305 teaching faculty members from institutions in 41 countries. The results of our study underscore the impact of the COVID-19 pandemic on GI endoscopy training, with $93.3 \%$ of respondents reporting a negative impact on endoscopy training. The suspension of elective procedures, primarily EGD and colonoscopy, had the greatest negative impact on endoscopy training, although several other factors played a role.

In addition, the quality of teaching was negatively impacted for various reasons, including pressure to complete procedures quickly $(49 \%)$ and challenges to the trainee-trainer interaction due to physical distancing and PPE requirements (48\%); furthermore, $27 \%$ of trainers reported that they were more likely to take the endoscope from the trainee. This survey highlights other factors independent of procedure volume that affect trainer-trainee interaction and, therefore, the quality of endoscopy teaching.

In response to the pandemic, training programs adjusted trainee schedules (56\%) and utilized virtual teaching platforms (46\%), but few (10\%) reported using endoscopy simulators to supplement endoscopy training. This may be due to the timing of the pandemic towards the end of the academic year in many programs, resources being diverted to patient care, and limited access to simulators. GI societies and training committees have long advocated the use of simulators, ${ }^{10}$ and the COVID-19 pandemic may accelerate their adoption and integration into endoscopy training programs. ${ }^{11}$ GI societies have also provided online resources to supplement hands-on training. ${ }^{12,13}$ The researchers believe that the increased role of endoscopy simulators and virtual education is likely to expand and improve access to training, patient safety, and leverage the flexibility of asynchronous teaching. ${ }^{14}$

These findings are consistent with those of a recent international survey of trainees, in which $71.9 \%$ of trainees were concerned that the COVID-19 pandemic could prolong training. ${ }^{8}$ In the current study, $71 \%$ of trainers expressed concern that the pandemic could impact their graduating trainees' preparedness to perform endoscopy independently, and 26\% felt that training may require extension. As the pandemic continues the long-term impacts on not only the seniors but also the new trainees are unclear. Traditionally, many training programs have relied on a model of completed case volumes as a surrogate marker of trainee proficiency, ${ }^{15}$ but the disruptive forces of the pandemic may require the adoption of more sophisticated methods of teaching and assessing proficiency. ${ }^{16,17}$ The Accreditation Council for Graduate Medical Education (ACGME) and American Board of Medical Specialties (ABMS) have recognized the impact of reduced procedures and endorsed the authority and judgment of clinical compe- 
tency committees (CCCs) and training PDs to determine the readiness of trainees for unsupervised practice. The judgment of endoscopy trainers is especially important when time-and volume-based educational standards may be challenged. ${ }^{18}$ Training directors must be particularly attentive to the needs of trainees who are at risk of not meeting competencies for safe practice, maximize training opportunities both in quantity and quality, and accurately assess trainees' readiness for unsupervised practice. The comments from respondents (Supplementary Material 6) highlighted the positive consequences of the pandemic, such as the increased use of telemedicine, virtual endoscopy education, greater experience in infection control, and stronger group cohesiveness.

This study also demonstrated geographic differences in the impact and response to the pandemic. European programs reported the lowest trainee participation in the endoscopy procedures. This may reflect the greater impact on European institutions where the burden of COVID-19 required trainees to assist in the care of COVID-19 patients, limiting their educational opportunities even beyond the reduction of procedure volume. A higher proportion of respondents from the Americas felt that endoscopy teaching was supported by their programs during the pandemic, despite a shortage of PPEs, suggesting that this difference may not be explained by the availability of resources. The reported differences in trainee participation in endoscopy during the pandemic are likely related to multiple factors such as the institutional policies regarding deployment of trainees and trainers to COVID-19 care units, local or national policies regarding the suspension of elective endoscopic procedures, and other obligations for endoscopy trainers in many parts of the world, including internal medicine duties in addition to endoscopy. The global differences among training programs may help GI experts prepare for future disruptions to endoscopic training and proactively rather than reactively adjust endoscopy training.

The strengths of this study include basing assessments from the trainers' perspectives. Most prior studies have focused on the perspective of the trainees; however, compared to trainees, instructors can compare and analyze educational progress more objectively and base their assessments on past experiences. Another strength of this survey is its global reach, encompassing 41 countries representing all WHO regions, as well as a robust response rate of $52.6 \%$. The limitations of this study, as with any survey study, include the possibility of reporting and recall bias. However, the majority of respondents were training directors who are usually well informed about procedure volumes and trainee involvement based on their formal roles and therefore best suited to represent the trainees. In the researchers' experience, trainees often express concerns about their trainers and PDs, but that this may not always occur.

In addition, not every region was equally represented, and the data were obtained during a specific period, which may have reflected the stage of the pandemic in a particular region. Although most respondents were in academic/university-based programs (70\%), the researchers feel that this is representative of the endoscopy training experience internationally, with a recent study showing that $68 \%$ of training programs in the United States are university-based. ${ }^{19}$

This study demonstrates that from the perspective of GI endoscopy trainers, the COVID-19 pandemic has had a significant negative impact on GI endoscopy training worldwide. The goal of this study was to capture the real-time impact of the pandemic on endoscopy training from the perspective of GI endoscopy trainers. Despite ongoing vaccination efforts, the impact of COVID-19 is likely to continue indefinitely, and the long-term consequences remain unclear. However, there have also been positive outcomes; this global challenge has brought the medical community together, from the institutional to the international level, adapting through innovation, dedication, and mutual support for the protection of patients, trainees, and colleagues. In this spirit, there should be a greater focus on interventions to optimize endoscopic training to ensure that trainees are adequately prepared for unsupervised practice while simultaneously protecting their safety and well-being.

Conflicts of Interest

Damien Tan Meng Yew and Christopher Khor are consultant for Boston Scientific.

The other authors have no potential conflicts of interest.

Funding

None.

Author Contributions

Conceptualization: Shivakumar Vignesh

Data curation: Amna Subhan Butt, Mohamed Alboraie, Shahriyar Ghazanfar

Formal analysis: ASB, MA, Bruno Costa Martins, SG, David Liao

Investigation: SV, ASB, MA, BCM, Alejandro Piscoya, Quang Trung Tran, Damien Tan Meng Yew, Pezhman Alavinejad, Edna Kamau, Ajay M Verma, Robin Mendelsohn, Christopher Khor Jen Lock, Alan Moss, DL, Christopher S. Huang, Franklin Tsai

Methodology: SV, ASB, MA, BCM, AP, QTT, DTMY, RM, CKJL, DL, CSH, FT

Project administration: SV, AP, QTT, PA, EK, AMV, CKJL, FT

Software: ASB, SG

Supervision: SV

Validation: ASB, MA, RM, FT

Visualization: SV, FT

Writing-original draft: SV, ASB, MA, BCM, AP, QTT, DTMY, SG, FT

Writing-review\&editing: SV, ASB, MA, BCM, AP, QTT, DTMY, SG, PA, EK, AMV, RM, CKJL, AM, DL, CSH, FT 
ORCID

$\begin{array}{ll}\text { Shivakumar Vignesh: } & \text { https://orcid.org/0000-0001-5190-6222 } \\ \text { Amna Subhan Butt: } & \text { https://orcid.org/0000-0002-7311-4055 } \\ \text { Mohamed Alboraie: } & \text { https://orcid.org/0000-0002-8490-9822 } \\ \text { Bruno Costa Martins: } & \text { https://orcid.org/0000-0002-0712-647X } \\ \text { Alejandro Piscoya: } & \text { https://orcid.org/0000-0002-4420-2419 } \\ \text { Quang Trung Tran: } & \text { https://orcid.org/0000-0001-8347-1614 } \\ \text { Damien Tan Meng Yew: } & \text { https://orcid.org/0000-0002-7282-0900 } \\ \text { Shahriyar Ghazanfar: } & \text { https://orcid.org/0000-0003-4957-8105 } \\ \text { Pezhman Alavinejad: } & \text { https://orcid.org/0000-0001-6857-6151 } \\ \text { Edna Kamau: } & \text { https://orcid.org/0000-0003-1653-6793 } \\ \text { Ajay M Verma: } & \text { https://orcid.org/0000-0002-6432-3357 } \\ \text { Robin B Mendelsohn: } & \text { https://orcid.org/0000-0002-5291-0191 } \\ \text { Christopher Khor: } & \text { https://orcid.org/0000-0002-1409-5691 } \\ \text { Alan Moss: } & \text { https://orcid.org/0000-0001-6551-2355 } \\ \text { David Wei Chih Liao: } & \text { https://orcid.org/0000-0001-5362-6953 } \\ \text { Christopher S Huang: } & \text { https://orcid.org/0000-0003-0582-7499 } \\ \text { Franklin C Tsai: } & \text { https://orcid.org/0000-0003-1670-665X }\end{array}$

\section{REFERENCES}

1. Valencia DN. Brief review on COVID-19: the 2020 pandemic caused by SARS-CoV-2. Cureus 2020;12:e7386.

2. Lassandro G, Palladino V, Amoruso A, Palmieri VV, Russo G, Giordano P. Children in coronaviruses' wonderland: what clinicians need to know. Mediterr J Hematol Infect Dis 2020;12:e2020042.

3. Cao W, Li T. COVID-19: towards understanding of pathogenesis. Cell Res 2020;30:367-369.

4. Adams JG, Walls RM. Supporting the health care workforce during the COVID-19 global epidemic. JAMA 2020;323:1439-1440.

5. Barberio B, Massimi D, Dipace A, Zingone F, Farinati F, Savarino EV. Medical and gastroenterological education during the COVID-19 outbreak. Nat Rev Gastroenterol Hepatol 2020;17:447-449.

6. Repici A, Pace F, Gabbiadini R, et al. Endoscopy units and the coronavirus disease 2019 outbreak: a multicenter experience from Italy. Gastroenterology 2020;159:363-366.e3.

7. Lui RN, Wong SH, Sánchez-Luna SA, et al. Overview of guidance for endoscopy during the coronavirus disease 2019 pandemic. J Gastroenterol Hepatol 2020;35:749-759.
8. Pawlak KM, Kral J, Khan R, et al. Impact of COVID-19 on endoscopy trainees: an international survey. Gastrointest Endosc 2020;92:925-935.

9. Forbes N, Smith ZL, Spitzer RL, et al. Changes in gastroenterology and endoscopy practices in response to the coronavirus disease 2019 pandemic: results from a North American survey. Gastroenterology 2020;159:772-774.e13.

10. Singh S, Sedlack RE, Cook DA. Effects of simulation-based training in gastrointestinal endoscopy: a systematic review and meta-analysis. Clin Gastroenterol Hepatol 2014;12:1611-1623.e4.

11. Siddiqui UD, Aslanian HR. The new virtual reality: advanced endoscopy education in the COVID-19 era. Dig Dis Sci 2020;65:1888-1891.

12. Palchaudhuri S, Gabre J, Prenner S, Klapproth JM. Adapting a GI fellowship to a pandemic: novel approaches to accommodating a novel virus. Dig Dis Sci 2020;65:1562-1565.

13. Keswani RN, Sethi A, Repici A, Messmann H, Chiu PW. How to maximize trainee education during the coronavirus disease-2019 pandemic: perspectives from around the world. Gastroenterology 2020;159:26-29.

14. Shah R, Satyavada S, Ismail M, et al. COVID-19 pandemic through the lens of a gastroenterology fellow: looking for the silver lining. Gastrointest Endosc 2020;92:394-398.

15. ASGE Standards of Practice Committee, Faulx AL, Lightdale JR, et al. Guidelines for privileging, credentialing, and proctoring to perform GI endoscopy. Gastrointest Endosc 2017;85:273-281.

16. ASGE Training Committee, Sedlack RE, Coyle WJ, et al. ASGE's assessment of competency in endoscopy evaluation tools for colonoscopy and EGD. Gastrointest Endosc 2014;79:1-7.

17. Miller AT, Sedlack RE, ACE Research Group. Competency in esophagogastroduodenoscopy: a validated tool for assessment and generalizable benchmarks for gastroenterology fellows. Gastrointest Endosc 2019;90:613-620.e1.

18. American Board of Medical Specialties. ABMS and ACGME joint principles: physician training during the COVID-2019 pandemic [Internet]. Chicago (IL); American Board of Medical Specialties; c2020 [updated 2020 April 10; cited 2021 Sep 1]. Available from: https://www.abms. org/news-events/abms-and-acgme-joint-principles-physician-trainingduring-the-covid-2019-pandemic/.

19. Atsawarungruangkit A. Association between proportion of US medical graduates and program characteristics in gastroenterology fellowships. Med Educ Online 2017;22:1364604. 